\title{
Electronic Systems and Offsite Touristic Activities Based on Geological Concepts: A Speculative Discussion ${ }^{\dagger}$
}

\author{
Carlos Alves ${ }^{1, *}$, Carlos Figueiredo ${ }^{2}$ and Jorge Sanjurjo-Sánchez ${ }^{3}$ \\ 1 LandS/Lab2PT-Landscapes, Heritage and Territory laboratory (FCT-UIDB/04509/2020) and Earth Sciences \\ Department/School of Sciences, University of Minho, 4710-057 Braga, Portugal \\ 2 CERENA-Centro de Recursos Naturais e Ambiente, FCT-UIDB/04028/2020, DEcivil, Instituto Superior \\ Técnico, University of Lisbon, 1649-004 Lisbon, Portugal; carlos.m.figueiredo@ist.utl.pt \\ 3 Instituto Universitario de Xeoloxía, Universidad de la Coruña, ESCI, Campus de Elviña, A Coruña, Spain; \\ jorge.sanjurjo.sanchez@udc.es \\ * Correspondence: casaix@dct.uminho.pt \\ + Presented at the 1st International Electronic Conference-Futuristic Applications on Electronics,1-30 \\ November 2020
}

Received: 25 August 2020; Accepted: 14 October 2020; Published: 30 October 2020

\begin{abstract}
The COVID-19 pandemic has caused havoc in many economic areas such as those related to tourism. This creates the need for alternative activities in this sector, especially given that it is not clear when will end the present emergency and there could new situations of this kind. We consider here two main possibilities (virtual models and remote observations) for tourism related to geological objects (including those used by humans) and processes. These approaches could help to promote remote-operated tourism in other celestial bodies, helping to promote this kind of enterprise. These activities could be prepared with variable connection to education (for publics with diverse age ranges), prompting their use at any time of the year (hence minimizing the issue of seasonality). Our discussion suggests that remote observations will be the most interesting option since they could potentially give the users an unlimited diversity of experiences, it might give higher return to local communities (but also higher loads on local environments) and they could find additional value in other geological applications. While our analysis is certainly very speculative at present, it can be submitted to falsification by the financial results.
\end{abstract}

Keywords: geological systems; virtual objects; remote operations; education; built environment; celestial bodies; SpaceX; COVID-19

\section{Introduction}

The COVID-19 pandemic has caused havoc in many economic areas such as those related to tourism. This creates the need for alternative offsite activities in this sector, especially given that it is not clear when will the present emergency end and it is not possible to rule out the occurrence of new situations of this kind.

But even before the pandemic there were proposals for "a changeover from the current massified cultural tourism to a creative tourism model" [1] (which presents several examples).

Offsite experiences will be, if successful, a valuable alternative for this situation as well as for other situations of temporary or permanent restrictions in access, including those affecting people with disabilities (so research on this subject will promote inclusivity of frequently excluded public).

Additionally, offsite alternatives could be useful for assessing places that cannot or should not accept a wide and frequent use by the public, either for conservation or access reasons. And, in this 
way, they can contribute to what has been recognized [2] as one of the major themes for the future of tourism: the combat to climate change.

We intend to discuss some possible offsite approaches related to tourism that interacts with geological objects, which will be used here in a very wide sense that includes, besides geological formations, geological materials used in the anthropogenic environment, as well as geological processes such as volcanic eruptions, and also equivalents in other celestial bodies.

\section{Analysis and Discussion}

We will consider two main possible approaches: virtual models and remote operations. However, they are not necessarily exclusive since, namely, remote operations could gather data to use in virtual models and the later could produce questions that will feed activities by remote operations. These approaches will be discussed in relation to geological objects and processes and also the extension of these considerations to locals out of planet Earth.

We will consider here geological objects both in their original geological contexts (terrains) and those displaced to a human setting (as elements of the built environment or of museums' collections).

Albeit it can be argued that looking at a picture or seeing a movie (or even reading a travel book) can be examples of virtual experiences, we will focus on attempts to go beyond the digital versions of these traditional ways.

Only virtual copies of real entities such as those mentioned at the beginning of this section will be considered. The virtual model of objects might be created with a limited number of visits to the entity (a single one in some cases).

Virtual models of outcrops or stone objects should ideally allow to manipulate the observation of these objects. They will allow to see what is exposed but they could, additionally, show other portions not visible to the public based in previous excavations (as is done in archaeological shows) or by interpretation from other information sources (e.g., boreholes, geophysical data).

It will be also possible to show previous instances of the object (this does require several visits, or the use of some model deemed suitable) and even features of the processes that lead to the creation of the object.

In terms of processes, such as volcanic eruptions, virtual models will either reproduce their previous instances (assuming there are several instances of information acquisition) or those resulting from models' predictions.

Any of the experiences (with objects or processes) can be enriched by interaction with information systems, including artificial intelligence and human agents.

The development of electronic systems for remote observation and manipulation can allow the user to interact with the actual geological object or processes in real-time.

This kind of approach necessarily involves the interaction with the real entity in its site for each experience and is based on interactions with other agents (human or robotics).

In principle, remote operations can include new, perhaps unseen and even unfathomed, initiatives from the user. Since human creativity and geological features are boundless, users could propose new observations and questions not foreseen by the authors of any virtual model.

In the case of objects, besides allowing the observations of different perspectives, there could be, under favourable conditions, the collection of samples to be shipped to the user or to museums' collections or the performing of field tests.

Remote observations could also allow the user to follow the development of a given geological process, for example, a volcanic eruption, in real-time. While there are some examples of remote observations of geological processes, such as the live cam at the Stromboli volcano [3], the approach envisioned here should include the possibility of offering to the users multiple choices in terms of perspective and observation distance (and hence of detail). The remote operations concerning these processes could also include the possibility of collecting samples of the resulting products (with the same potential destinations mentioned above).

We can extend, as is frequently done, our considerations to objects and processes that can be described by geological models in locations out of planet Earth. There is already a growing interest 
in the commercial exploration of spaceflight, of which SpaceX will be the most known name, having already been involved in launching humans [4] and also with well-known planes for a possible colonization of Mars, for which there are also other proposals [5].

Spaceflights will be certainly hardly accessible for wide swaths of the public in the coming years, even to the moon, but the information acquired could contribute to models that simulate these out of earth bodies and there could be variations where a significantly larger portion of the public could be involved in remote operations. Furthermore, both virtual models and remote operations could be performed in bodies where it is deemed at this point too risky for human crews. This could be a mutualistic relation in that the expansion to a wider audience helps to promote the funding of further missions. It will be perhaps relevant to highlight that the uses presented here are independent of the actual establishment of human colonies in other celestial body.

\section{Final Considerations}

The activities discussed above could be prepared with variable connection to education (for publics with diverse age ranges).

There are several situations where they can be performed at any time of the year (hence minimizing the issue of seasonality), albeit, in cases like remote operations concerning volcanic eruptions, the available activities will be affected by the evolution of the volcanic system.

Our discussion suggests that remote observations will be the most interesting options since they could potentially give the users an unlimited diversity of experiences. It will be also the one with more potential for the public with specific needs (locomotive, hearing, vision) as the systems could be more flexibly tailored.

Remote operations would also be more favourable to local economies as they always involve a local interaction and hence require some kind of permanent local structure.

That also means that they could have a higher toll on the local environment (but they could converge with efforts to guard the considered objects).

Regarding sustainability, the evaluation will be affected by the many variables involved but virtual models seem to have a lower impact.

Remote operations seem to be the one requiring higher investment. However, the potential use of these remote electronic systems in other economic areas such as mineral exploitation and environmental assessment and monitoring, and space exploration, might help to make these investments financially viable.

We propose that while our analysis is certainly very speculative at present, it can be submitted to falsification: if correct, the public will pay for these touristic activities. To further strengthen our assessment, these activities must be financially viable without specific government funding (albeit they could receive indirect government funding through, for example, the educational system or activities for the senior population).

Author Contributions: All authors contributed to this work.

Funding: The Lab2PT-Landscapes, Heritage and Territory laboratory (funded by FCT- UIDB/04509/2020) is supported by the Portuguese FCT - "Fundação para a Ciência e a Tecnologia". The authors also gratefully acknowledge the support of the CERENA (funded by a strategic project of the FCT-UIDB/04028/2020) and the LAMPIST of the DECivil, Instituto Superior Técnico, University of Lisbon, Portugal. The University Institute of Geology of the University of A Coruña (Spain) receives support from the Xunta de Galicia from the program "Consolidación y estructuración de unidades de investigación competitivas: Grupos de potencial de crecimiento" (ED431B 2018/47) and Redes de investigación (R2017/008).

Conflicts of Interest: The authors declare no conflict of interest.

\section{References}

1. Remoaldo, P.; Matos, O.; Freitas, I.; Gôja, R.; Araújo Alves, J.; Ribeiro, V.; Pereira, M.; Xavier, C. An International Overview of Certified Practices in Creative Tourism in Rural and Urban Territories. J. of Hospitality \& Tourism Research 2020, 109634802095079, doi:10.1177/1096348020950792. 
2. Prideaux, B.; Thompson, M.; Pabel, A. Lessons from COVID-19 can prepare global tourism for the economic transformation needed to combat climate change. Tour. Geogr. 2020, 22, 667-678, doi:10.1080/14616688.2020.1762117.

3. Available online: https://www.skylinewebcams.com/en/webcam/italia/sicilia/messina/stromboli.html (accessed on 11 October 2020).

4. Witze, A. SpaceX to launch astronauts - and a new era of private human spaceflight. Nature 2020, d41586020-01554-8, doi:10.1038/d41586-020-01554-8.

5. Impey, C. Mars and Beyond: The Feasibility of Living in the Solar System. In The Human Factor in a Mission to Mars; Szocik, K., Ed.; Space and Society; Springer: Manhattan, New York City, USA, 2019; pp. 93-111 ISBN 978-3-030-02058-3. Doi:10.1007/978-3-030-02059-0_5.

(C) 2020 by the authors. Submitted for possible open access publication under the terms and conditions of the Creative Commons Attribution (CC BY) license (http://creativecommons.org/licenses/by/4.0/). 